\title{
EDITORIAL
}

\section{Como Enfrentamos a COVID-19 no Hospital Santa Izabel (HSI)}

\author{
How We Face the COVID-19 in the Santa Izabel Hospital
}

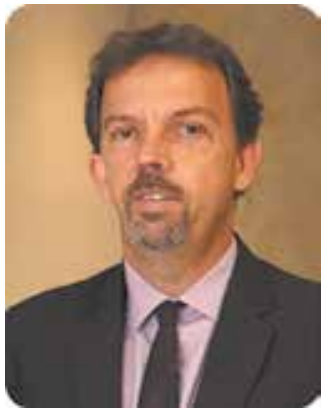

\author{
José Ricardo Madureira ${ }^{1}$ \\ ${ }^{1}$ Diretor Técnico Assistencial do Hospital Santa Izabel; Salvador, Bahia, Brasil
}

No final de dezembro de 2019, o mundo foi surpreendido com as primeiras notícias de uma nova doença na cidade de Wuhan, província de Hubei na China, que se espalhou rapidamente pelo mundo e foi logo elevada à categoria de pandemia. Até aquele momento, pouco conhecimento tinhase a respeito do seu agente etiológico, modo de transmissão, aspectos imunológicos, de fisiopatologia, clínicos, prognóstico, tratamento e prevenção.

Rapidamente, assistimos ao avançar desta condição no globo: o efeito devastador sobre uma população vulnerável por comorbidades, mas ao mesmo tempo também o assustador efeito em um elevado número de jovens surpreendentemente acometidos por evolução fatal da doença, fazendo cientistas e autoridades reconhecerem não se tratar de uma doença simples provocando sintomas de vias aéreas superiores, mas todo um espectro de condições clínicas variadas, associadas principalmente a cascata inflamatória desencadeada e afetando diversos sistemas.

Ao mesmo tempo que informações começaram a ser melhor analisadas, simultaneamente a todo esforço de médicos e profissionais de saúde em busca da melhor forma de tratar os pacientes, também os sistemas de saúde pelo mundo, do mesmo modo, foram colocados à prova, pois assistimos aos efeitos da pandemia no enfraquecimento sobre organizações de saúde e sistemas de saúde, gestores se depararam com uma condição que ao mesmo tempo põe em cheque a capacidade de gerenciamento de instituições e nações, face aos problemas de escassez de recursos de toda ordem e consequências econômicas e sociais.

O Hospital Santa Izabel, inserido no contexto como uma estrutura

Correspondence addresses: Dr. José Ricardo Madureira ricardo.madureira@santacasaba.org.br

\section{Copyright}

(C) 2020 by Santa Casa de Misericórdia da Bahia.

All rights reserved.

ISSN: 2526-5563 complexa de atenção terciária e filantrópica por natureza, teve de adaptarse rapidamente a partir de fevereiro de 2020 para atender a demanda simultânea dos Sistemas Único de Saúde (SUS) e de Saúde Suplementar, modificando e estruturando quase toda funcionalidade hospitalar e de seus processos, sendo fundamental a criação de um Comitê Gestor de Crise, com participação de todos os seus diretores, passando pelas diversas lideranças de todas as áreas de assistência e serviços de apoio. 
Passados três meses desde o nosso primeiro atendimento confirmado, assistimos a inúmeros desafios e talvez o mais difícil foi o de educar, encorajar e dar condição à equipe, já sensibilizada pelas notícias mundiais de vidas ceifadas entre trabalhadores. Tivemos que nos adaptar às perdas na escala de trabalho, tanto por adoecimento quanto por desligamentos voluntários de colaboradores, alguns temendo seu próprio destino, outros sobrecarregados ou psicologicamente afetados frente a tantos desafios.

Foram diversas reuniões que se modificaram de presenciais a virtuais, realizadas semanalmente e algumas de forma extraordinária, colegiada, multidisciplinar e baseada em conhecimento científico vigente, e nelas pautamos a busca incessante pelo melhor resultado possível aos nossos pacientes e proteção aos colaboradores. Desde logo foi necessário um esforço para rápida atualização de protocolos, fluxos e processos operacionais considerando a descoberta e atualização de informações à medida que o conhecimento foi se somando.

Tão logo iniciado o internamento de pacientes acometidos, tivemos de adaptar unidades, tornandoas coortes para isolamento de pacientes, preocupados em evitar a contaminação intra-hospitalar, tal cenário foi replicado desde as emergências, incluindo unidades de internação e de terapia intensiva, além da separação do público adulto e pediátrico, fato este que novamente exigiu criatividade e adaptabilidade considerando o aspecto secular da nossa Instituição.

Logo no início deste cenário, deparamo-nos com a ameaça de rompimento de ressuprimentos de equipamentos de proteção individual e, nas últimas semanas, com o crescente volume de pacientes críticos, a ameaça de falta de insumos farmacêuticos como os bloqueadores neuromusculares, sedativos e analgésicos. Entretanto, em todas as vezes, mais uma vez o assunto foi superado com a colaboração de médicos intensivistas, farmacêuticos e equipe de enfermagem, além de monitoramento pela equipe de compras e abastecimento.

À medida que avançava a chegada de pacientes críticos nas nossas emergências, passamos a lidar com a incapacidade de aumento de leitos pela dificuldade de contratação de equipe assistencial. Nesse momento, usamos da criatividade para adaptar espaços nas emergências, objetivando o suporte para pacientes graves. Praticamente metade dos leitos hospitalares foram dedicados aos cuidados de portadores da COVID-19.

No campo dos cuidados, foi importante a atuação do corpo clínico, com médicos de várias especialidades unindo-se para o atendimento, evolução e prescrição de pacientes, rapidamente trazendo as melhores evidências na criação de protocolos, colaborando na educação e treinamento, no atendimento da emergência e sugerindo sempre as melhores rotinas, além da adaptação às novas realidades como boletins médicos de pacientes aos seus familiares sendo realizados a distância.

No campo do ensino, foi oportuno ver que muito se avançou no uso da tecnologia para discussões, aulas e debates, através do suporte de uma gama de aplicativos com esta finalidade, e parte dos treinamentos do corpo discente puderam ser mantidas. Os preceptores e residentes tiveram papel importante também na assistência direta aos pacientes. Na pesquisa também fomos inseridos em trials para avaliação de terapias.

Ainda não sabemos por quanto tempo estaremos envolvidos neste cenário de crise, mas com certeza estamos presenciando um momento singular na história de medicina e da humanidade, legados que ficarão reforçados pela capacidade de organização, resiliência, censo crítico face ao efeito da tecnologia e a avalanche de informações, mas, sem dúvida, marcados pela capacidade do ser humano de responder de forma rápida, como nunca antes na história, a um desafio desta natureza.

Por fim, teremos agora um novo desafio que é retomar as atividades habituais do Hospital, já que alguns serviços foram interrompidos ou reduzidos em volume, rotinas como checagem de temperatura na entrada dos clientes e colaboradores, distanciamento nas salas de espera, vigilância na higiene 
das mãos e de estruturas, uso sistemáticos de máscaras e protetores faciais alteram a dinâmica prévia da Instituição.

Importante portanto destacar como toda crise é capaz de nos fazer refletir, modificar comportamentos e atitudes, tornando pessoas, profissionais, sociedades e nações melhores. Assistimos à solidariedade de empresas, valorização do trabalho de profissionais de saúde e, por fim, ao reconhecimento de como é fundamental o investimento e valorização no trabalho de pesquisadores e cientistas envolvidos em estudar as soluções, aplicando pesquisas metodologicamente corretas, baseadas em princípios bioéticos, capazes de responder rapidamente a demandas da humanidade neste mundo em permanente transformação. 